\title{
Modeling Effect of Traffic on Increased Losses from Fire Incidents using Matlab Software
}

\author{
Mehdi Salehi Ghara Mohammadi \\ Faculty of Engineering \\ Department of Industrial Engineering \\ Energy Institute of Higher Educations, Saveh, Iran
}

\author{
Mostafa Adelizadeh \\ PhD Student of Environment Management \\ Department of Environmental Education \\ Islamic Azad University, Roodehen Branch, \\ Tehran, Iran
}

\begin{abstract}
This study aims to address intersections of high-density fire zones with the most traveled roads in Karaj city during peak traffic hours. These zones and roads have been identified through collection of field data and desk research. Then resulting map of two areas, i.e. the most travelled roads and high-density fire zones were superposed and the intersection was obtained that represents the high-risk region. As result, in order to mitigate and prevent future financial losses and mortalities in this region, the recommendations are made with regard to traffic method, and requirements of rule of law to prevent fire incidents and their expansion in available places on the region. The neural network model was used to predict degree of losses. The results suggest that this network predicts the event with accuracy of 0/9938.
\end{abstract}

\section{Keywords}

Matlab, Traffic, Fire incidents, Golden time

\section{INTRODUCTION}

Human being has long been searching for security and safety. $\mathrm{He}$ has tried to provide himself better condition for life by dominance on nature and its components. And today, technology has become a great tool toward reaching this end, enhancing his abilities and facilitating his journey to new era of growth and development. Although this new capability has helped the human being to achieve dominance on nature, it has had many disadvantages for environment, due to unlimited demands of people. In modern world, safety is regarded an inclusive and diverse knowledge. Application of this knowledge guarantees the present and future of human life. And thus, it is essential to apply the state of the art innovations and findings in practice and use the best equipments and facilities in hand.

The literature review reveals that traffic volume has direct relation with industrialization, because industrial development represents the rise of diversity and number of vehicles, leading to traffic and congestion. The concept of traffic management was started in 1930s in the United States and then expanded to other courtiers during 1950s and 1960s.

The consequence of traffic congestion is wasting time. The costs of such traffic congestion, in particular, increased costs of damages caused by fire accidents will affect, directly or indirectly, all members of the society and finally, the community as a whole. And as more time is taken to reach the forces or firefighters to the fire scene, this cost will be increased too.

\section{LITERATURE REVIEW}

Alireza Sarvari Sayyed et al. (2019) in their article 'A new tunnel fire detection and suppression system based on camera image processing and water mist jet fans' investigates economic aspect of firefighting systems in tunnels and suggest that as the conventional equipment to extinguish fire, i.e. water mist system, is expensive and not-affordable, it is better to use the new proposed jet fan system[1].

CahngLiu et al. (2019) in the article 'Study on emergency ventilation for train fire environment in metro interchange tunnel' investigate safety of tunnels during fire accidents and suggest that the semi-hybrid ventilation provides the safe evacuation environment, using TVFs cooperation, jet flow and down-stream ceiling extraction, compared to other systems. This ventilation mode eliminates the smoke effectively, maintaining the temperature, toxic gases, visibility and radiant head flux at a safe level in upstream of fire. In addition, optimal use of ceiling duct will improve the efficiency of smoke exhaust as far as possible downstream of the middle fire. Finally, an emergency response plans was proposed for different scenarios of fire accidents, including equipment activation and passenger evacuation strategies, providing the guideline to create safe path of evacuation along the fire environment in tunnel[2].

MinjiChoi et al. (2019) in an article 'Optimal route selection model for fire evacuations based on hazard prediction data' investigated routes of evacuation during fire accidents in public spaces[3].

JunliLuoa et al. (2019) in an article 'Effect of vehicular blocking scene on smoke spread in the longitudinal ventilated tunnel fire' simulated the smoke behavior in tunnels and demonstrated that maximum temperature, smoke spread range under ceiling of tunnel was affected significantly by blocking area ratio[4].

ZhiguoYan et al. (2018) in an article 'Numerical study on the smoke control, using point extraction strategy in a large crosssection tunnel in fire' introduce PSE system to exhaust smoke from tunnels, using a simulation of fire characteristics such as temperature, smoke, etc. They conclude that transverse fire locations affect slightly the evacuation environment, due to large cross-section[5].

Moreover, Tanaporn Tanachawengsaku et al. (2016) in an article 'A Simulation Study on Fire Evacuation Routes in Primary Stage for a Historic Canal Residential Area' explored the space between buildings and homes to access the fire location and helping people[6].

In another study called 'Scene Design and Simulation Analysis of Fire Accident in Underwater Tunnel' QiZhang et al. (2016) examined fire behavior in tunnels, evacuation conditions and fire control in such places. Using FDS+EVAC, they simulated and analyzed fire accidents and personnel evacuations, to give a good picture of identifying fire risks, developing fire prevention programs and construction of tunnel under water for post-operation[7]. 
J.PesicaDarko et al. (2016) in a research called 'Large Eddy Simulation of wind flow impact on fire-induced indoor and outdoor air pollution in an idealized street canyon' investigates role of wind on fire dispersion and degree of damages to surrounding buildings. The numerical results show that there is strong interaction between wind flow and fire plume flow within canyon. The patterns of flow field in narrow canyon limit the air flow, causing dispersion of plume inside and over canyon, as well as pushing smoke into the buildings[8].

And finally, ZhengWei (2013) examines safety and protection of indoor commercial sidewalks and poinst to need of using appropriate equipments to control fire in these overcrowded urban areas[9].

\section{METHODOLOGY}

This is a desk research with field data gathered in Karaj Fire Department. This data include types of fire incidents, number of fire incidents in past few years which information are available only since 2017 because the mission reports are not systematic, number of operating stations and coverage area, as well as number of fire trucks dispatched for mission, time taken to travel and reach the incident location, time taken for firefighting operations, number of firefighters dispatched for mission and the station with maximum number of missions.
Alborz is 31 st province of Iran. It was formed officially after the Parliamentary approval on June 23, 2010 and its center is Karaj city. Karaj is situated $20 \mathrm{~km}$ west of Tehran and with the population of 1,614,626 is the forth populated city of Iran following Tehran, Mashhad and Isfahan. On August 13, 2010, Mahmood Ahmadinejad, the then president announced formation of Alborz Province in a letter to the Ministry of Interior. This province is named after Alborz Mountain located in north of province. On September 13, 2010 Alborz Province governor office was officially started to work with presence of Minister of Interior. Isa Farhadi was selected as the first governor of this province. Alborz Television Channel was launched on October 2012 with broadcasting 3 hours a day and it increased to 8 hours in 2013. It was officially launched on May 25, 2013 with 10 hours broadcast a day. It was called channel of unity and empathy because of diversity of ethnicity in this province.

In this study, for data collection, the researchers attended in research center of Karaj Firefighting Department (Prevention Office) and having studied the statistical information related to fire incidents and accidents, they could obtain the data only for period of 2017 to 2018 because the archive system was an emerging system in which data are exchanged online in an integrated network and reports of fire incidents are sent to prevention office each day. Then the gathered data was verified by head of prevention office.

Table 1: Karaj population

\begin{tabular}{|c|c|c|c|c|c|c|}
\hline No. & City & County & $\begin{array}{c}\text { Population } \\
2006\end{array}$ & $\begin{array}{c}\text { Population } \\
2010\end{array}$ & $\begin{array}{c}\text { Population } \\
2016\end{array}$ & Ranking \\
\hline 1 & Karaj & Karaj & $1, T V V_{6} Y D_{0}$ & 1.914 .949 & 1.09Y.Y9Y & 1 \\
\hline 2 & Fardis & Fardis & & & $11161 V F$ & 1 \\
\hline 3 & Kamal shahr & Karja & A.GTSD & $1.9694 \pi$ & 141.999 & 2 \\
\hline 4 & Nazarabad & Nazarabad & $9 V .914$ & $1 . V_{6} 1.9$ & $119601 Y$ & 1 \\
\hline 5 & Mohammad shahr & Karaj & Ar, YY & $1 \cdots .019$ & 1196411 & 3 \\
\hline 6 & Mahdasht & Karaj & prol.. & 01.011 & 9Y.91. & 4 \\
\hline 7 & Meshkin dasht & Fardis & 94.91. & DrGF. & $9 Y_{6} \ldots 0$ & 2 \\
\hline 8 & Hashtgerd & Savojbolagh & Fagrtr & $01.90 r$ & $\Delta 0,94$. & 1 \\
\hline 9 & Chahar bagh & Savojbolagh & $\Delta \Delta, 94$. & $96 V Y Y$ & $Y \Lambda_{6} \wedge Y \wedge$ & 2 \\
\hline 10 & Shahre jadide hashtgerd & Savojbolagh & 10.919 & TYGYYY & FT,IFY & 3 \\
\hline 11 & Eshtehard & Eshtehard & 196911 & $r r_{6} \cdot 1$. & rq.99r & 1 \\
\hline 12 & Garmdare & Karaj & Tr.VTA & ITGYYA & TYGYY & 5 \\
\hline 13 & Golsar & Savojbolagh & $11, .14$ & Kr. F.V & 1 TrVYO & 4 \\
\hline 14 & Kouhsar & Sovojbolagh & $V_{6} V \Delta V$ & $\Lambda_{6} r \cdot r$ & 1.694. & 5 \\
\hline 15 & Tankaman & Nazarabad & FGVFY & $4,19$. & 4.904 & 2 \\
\hline 16 & Taleghan & Taleghan & r.YN1 & r.YII & $r . \Delta Y \Delta$ & 1 \\
\hline 17 & Asara & Karaj & Fr. & $v \cdot 1$ & 1.449 & 6 \\
\hline
\end{tabular}


Table 2: Statistics of fire incidents and accidents in Karaj

\begin{tabular}{|c|c|c|c|c|c|}
\hline No & Station & $\begin{array}{l}\text { Number of fire } \\
\text { incidents }\end{array}$ & Percentage & $\begin{array}{l}\text { Number of } \\
\text { accidents }\end{array}$ & Percentage \\
\hline 1 & 101 & 200 & 3.799 & 162 & 2.799 \\
\hline 2 & 102 & 245 & 4.569 & 145 & 2.505 \\
\hline 3 & 103 & 190 & 3.543 & 254 & 4.389 \\
\hline 4 & 104 & 405 & 7.533 & 288 & 4.976 \\
\hline 5 & 105 & 189 & 3.524 & 208 & 3.594 \\
\hline 6 & 106 & 141 & 2.629 & 196 & 3.386 \\
\hline 7 & 107 & 195 & 3.636 & 254 & 4.389 \\
\hline 8 & 108 & 282 & 5.295 & 264 & 4.561 \\
\hline 9 & 109 & 239 & 4.475 & 260 & 4.492 \\
\hline 10 & 110 & 361 & 6.732 & 155 & 2.678 \\
\hline 11 & 111 & 211 & 3.935 & 248 & 4.285 \\
\hline 12 & 112 & 141 & 2.629 & 258 & 4.458 \\
\hline 13 & 113 & 248 & 4.625 & 198 & 3.421 \\
\hline 14 & 114 & 180 & 3.356 & 192 & 3.317 \\
\hline 15 & 115 & 84 & 1.566 & 176 & 3.041 \\
\hline 16 & 116 & 124 & 2.312 & 176 & 3.041 \\
\hline 17 & 117 & 158 & 2.946 & 130 & 2.462 \\
\hline 18 & 118 & 99 & 1.846 & 121 & 2.090 \\
\hline 19 & 119 & 135 & 2.517 & 241 & 4.164 \\
\hline 20 & 120 & 238 & 4.438 & 243 & 4.199 \\
\hline 21 & 121 & 201 & 3.748 & 170 & 2.973 \\
\hline 22 & 122 & 151 & 2.816 & 304 & 5.253 \\
\hline 23 & 123 & 269 & 5.016 & 263 & 4.544 \\
\hline 24 & 124 & 168 & 3.133 & 216 & 3.732 \\
\hline 25 & 125 & 54 & 1.007 & 19 & .328 \\
\hline 26 & 126 & 16 & .298 & 16 & .276 \\
\hline 27 & 127 & 7 & .130 & 5 & .086 \\
\hline 28 & 151 & 84 & 1.566 & 189 & 3.265 \\
\hline 29 & 152 & 50 & .932 & 68 & 1.175 \\
\hline 30 & 153 & 48 & .895 & 61 & 1.054 \\
\hline 31 & 154 & 100 & 1.864 & 74 & 1.278 \\
\hline 32 & 155 & 50 & .932 & 61 & 1.054 \\
\hline 33 & 156 & 135 & 2.517 & 172 & 2.972 \\
\hline
\end{tabular}

Source: Karaj Fire and Safety organization. Date of reports on total fire incidents and accidents of Karaj city is from Mars 21,2017 to Mars 20, 2018. 
Table 3: Organizational operations statistics

\begin{tabular}{|c|c|c|c|c|c|c|c|}
\hline No. & \multicolumn{2}{|c|}{$\begin{array}{l}\text { Number of fire incidents and } \\
\text { accidents }\end{array}$} & \multirow{2}{*}{$\begin{array}{c}\text { Total dispatched fire } \\
\text { trucks } \\
246\end{array}$} & \multirow{2}{*}{$\begin{array}{c}\begin{array}{c}\text { Number of } \\
\text { firefighters }\end{array} \\
15572\end{array}$} & \multirow{2}{*}{$\begin{array}{c}\text { Number of } \\
\text { rescued }\end{array}$} & \multirow{2}{*}{$\begin{array}{c}\begin{array}{c}\text { Number of } \\
\text { injured }\end{array} \\
120\end{array}$} & \multirow{2}{*}{$\begin{array}{c}\text { Mortality } \\
3\end{array}$} \\
\hline 1 & Fire & 5399 & & & & & \\
\hline 2 & Accident & 5783 & 115 & 17835 & 3863 & 433 & 115 \\
\hline & Total & 1182 & 361 & 33407 & 3943 & 553 & 118 \\
\hline
\end{tabular}

Table 4: Time taken to reach the operating forces of Station 4 to place of accident

\begin{tabular}{|c|c|c|c|c|c|c|c|c|c|c|c|c|c|}
\hline Time taken to reach $(\mathrm{min})$ & $3-5$ & $5-6$ & $6-7$ & $7-8$ & $8-9$ & $9-10$ & $10-11$ & $11-12$ & $12-13$ & $13-14$ & $14-15$ & $15-16$ & More than 16 \\
\hline Number of missions & 75 & 61 & 41 & 24 & 9 & 17 & 11 & 2 & 0 & 1 & 1 & 3 & 5 \\
\hline
\end{tabular}

Table 5: Time taken to reach the operating forces of Station 4 to place of fire incidents

\begin{tabular}{|c|c|c|c|c|c|c|c|c|c|c|c|c|c|}
\hline Time taken to reach (min) & $3-5$ & $5-6$ & $6-7$ & $7-8$ & $8-9$ & $9-10$ & $10-11$ & $11-12$ & $12-13$ & $13-14$ & $14-15$ & $15-16$ & $16-38$ \\
\hline Number of missions & 113 & 61 & 41 & 24 & 9 & 17 & 11 & 2 & 0 & 1 & 1 & 3 & 6 \\
\hline
\end{tabular}

Table 6: Fire incidents statistics of firefighting stations in 2017

\begin{tabular}{|c|c|c|c|c|c|c|}
\hline Station & Reports & Numbers & Trucks & Rescued & Injured & Mortality \\
\hline Station1 & 200 & 466 & 162 & 0 & 3 & 0 \\
\hline Station2 & 245 & 1000 & 229 & 0 & 3 & 0 \\
\hline Station3 & 190 & 459 & 158 & 2 & 5 & 0 \\
\hline Station4 & 405 & 946 & 268 & 0 & 7 & 0 \\
\hline Station5 & 189 & 596 & 155 & 0 & 3 & 0 \\
\hline Station6 & 141 & 434 & 162 & 2 & 2 & 0 \\
\hline Station7 & 195 & 575 & 197 & 3 & 7 & 1 \\
\hline $\begin{array}{c}\text { Station } \\
8\end{array}$ & 282 & 808 & 297 & 0 & 6 & 0 \\
\hline Station9 & 239 & 833 & 262 & 0 & 4 & 0 \\
\hline Station10 & 361 & 790 & 297 & 1 & 5 & 0 \\
\hline Station11 & 211 & 599 & 231 & 10 & 4 & 0 \\
\hline Station12 & 141 & 306 & 86 & 0 & 5 & 0 \\
\hline Station13 & 248 & 787 & 277 & 0 & 2 & 0 \\
\hline Station14 & 180 & 437 & 142 & 3 & 3 & 0 \\
\hline Station 15 & 84 & 144 & 49 & 0 & 2 & 0 \\
\hline Station16 & 124 & 277 & 109 & 0 & 5 & 0 \\
\hline Station17 & 158 & 440 & 151 & 1 & 8 & 0 \\
\hline Station18 & 99 & 236 & 86 & 0 & 4 & 0 \\
\hline Station19 & 135 & 335 & 135 & 1 & 5 & 0 \\
\hline Station20 & 238 & 495 & 188 & 3 & 5 & 0 \\
\hline Station21 & 201 & 496 & 151 & 19 & 2 & 0 \\
\hline Station22 & 151 & 415 & 145 & 1 & 1 & 0 \\
\hline Station23 & 169 & 815 & 317 & 6 & 14 & 0 \\
\hline
\end{tabular}




\begin{tabular}{|c|c|c|c|c|c|c|}
\hline Station24 & 168 & 380 & 158 & 0 & 2 & 0 \\
\hline Station 25 & 54 & 98 & 25 & 0 & 2 & 0 \\
\hline Station26 & 16 & 31 & 9 & 0 & 0 & 0 \\
\hline Station 27 & 7 & 17 & 7 & 0 & 0 & 0 \\
\hline Station51 & 84 & 120 & 36 & 5 & 0 & 0 \\
\hline Station52 & 50 & 117 & 38 & 1 & 0 & 0 \\
\hline Station53 & 48 & 93 & 33 & 0 & 0 & 0 \\
\hline Station54 & 100 & 169 & 27 & 0 & 4 & 0 \\
\hline Station55 & 50 & 59 & 22 & 0 & 0 & 0 \\
\hline Station56 & 135 & 265 & 89 & 8 & 2 & 2 \\
\hline Total & 5398 & 14038 & 4698 & 66 & 115 & 3 \\
\hline
\end{tabular}

Table 7: accidents statistics of firefighting stations in 2017

\begin{tabular}{|c|c|c|c|c|c|c|}
\hline Station & Reports & Numbers & Trucks & Rescued & Injured & Mortality \\
\hline Station1 & 162 & 304 & 98 & 54 & 28 & 0 \\
\hline Station2 & 145 & 314 & 93 & 85 & 8 & 3 \\
\hline Station3 & 254 & 388 & 126 & 148 & 5 & 3 \\
\hline Station4 & 288 & 445 & 108 & 167 & 17 & 4 \\
\hline Station5 & 208 & 453 & 103 & 120 & 3 & 1 \\
\hline Station6 & 196 & 406 & 142 & 104 & 4 & 3 \\
\hline Station7 & 254 & 434 & 155 & 146 & 19 & 2 \\
\hline Station8 & 264 & 649 & 240 & 111 & 26 & 8 \\
\hline Station9 & 260 & 616 & 210 & 133 & 16 & 5 \\
\hline Station 10 & 155 & 225 & 92 & 64 & 10 & 5 \\
\hline Station11 & 248 & 598 & 191 & 139 & 9 & 5 \\
\hline Station12 & 258 & 386 & 106 & 178 & 31 & 4 \\
\hline Station13 & 198 & 561 & 205 & 115 & 9 & 9 \\
\hline Station14 & 192 & 356 & 122 & 75 & 14 & 1 \\
\hline Station 15 & 176 & 257 & 73 & 61 & 1 & 1 \\
\hline Station16 & 171 & 315 & 127 & 90 & 18 & 6 \\
\hline Station17 & 130 & 362 & 123 & 51 & 19 & 11 \\
\hline Station18 & 121 & 240 & 93 & 70 & 18 & 4 \\
\hline Station19 & 241 & 455 & 176 & 190 & 21 & 1 \\
\hline Station20 & 243 & 403 & 157 & 85 & 6 & 6 \\
\hline Station21 & 170 & 268 & 102 & 70 & 12 & 3 \\
\hline
\end{tabular}




\begin{tabular}{|l|c|c|c|c|c|c|}
\hline Station22 & 304 & 609 & 222 & 209 & 9 & 1 \\
\hline Station23 & 263 & 546 & 196 & 185 & 15 & 7 \\
\hline Station24 & 216 & 408 & 147 & 63 & 7 & 3 \\
\hline Station25 & 19 & 25 & 4 & 9 & 0 & 0 \\
\hline Station26 & 16 & 27 & 8 & 1 & 0 & 0 \\
\hline Station27 & 5 & 14 & 5 & 0 & 3 & 0 \\
\hline Station51 & 189 & 288 & 78 & 119 & 16 & 0 \\
\hline Station52 & 68 & 147 & 45 & 36 & 4 & 3 \\
\hline Station53 & 61 & 102 & 40 & 36 & 1 & 0 \\
\hline Station54 & 74 & 107 & 29 & 33 & 6 & 0 \\
\hline Station55 & 61 & 63 & 16 & 35 & 1 & 0 \\
\hline Station56 & 172 & 347 & 114 & 100 & 8 & 0 \\
\hline Total & 5782 & 11118 & 3746 & 3082 & 364 & 99 \\
\hline
\end{tabular}

\section{DISCUSSION}

When the data are collected, extracted and classified, the tables of frequency distribution and distribution ratio are prepared. Now, it's time to begin a new phase in research process, known to data analysis. In this step, it should be noted that researcher analyzes the data and information in direction of objectives, finding answers for research questions and interpreting the hypotheses.

The aim of data analysis is exploring the phenomena and the relations between variables. Analysis is composed of two steps: 1. Data analysis and 2. Interpretation of results and hypothesis tests. Each step can be carried out differently with regard to type of information and data collection methods. However, the most important factors in this step, is the pattern developed by researcher and the selected method for analysis. The pattern based on which the method of analysis is selected determine that what information are analyzed and how. Method of data analysis is chosen according to goals, hypotheses and pattern of analysis. Moreover, using different tools in analysis can improve accuracy of selected method. In other word, the best method should be applied along with the most appropriate tool, because selection of method and tool is of great importance and the results are heavily dependent upon the methods and tools.

Considering the superimposition of traffic volume map (Map 1) and Karaj map (Map 2), the peak traffic points in operational limit of firefighting Station No.4 in Karaj were obtained and as result, the peak traffic points within operational limit are as follows:
* Mehrshar, in distance of Phase 1 \& 2, Valiasr Boulevard (municipality) from first of Shahid Motahhari boulevard to first of 111 Street in which the reported traffic volume is $415 / 25$ automobiles (mean of traveling cars in a peak traffic hour).

* Mehrshahr, Phase 2, end of Shahid Motahhari Boulevard, intersection of Golestan 1 Road, in which volume of traffic reported is 2765 automobiles.

* Mehrshahr, Phase 4 (north-south), Shahid Karim Akhoundi Street, from first of Golha junction to Karaj- Qazvin railroad, in which volume of reported traffic is $1177 / 93$ automobiles.

* Mehrshahr, Imam Khomeini Boulevard (Eram) (northsouth), from limit of Mehrshar bridge to Sharifi Street (2nd East), number of 1908/33 automobiles is reported.

* Mehrshahr, Imam Khomeini Boulevard (Eram) (northsouth), from limit of Kaj Street to 5th East Street, number of reported traffic volume is $2386 / 19$ automobiles.

* Mehrshahr, Imam Khomeini Boulevard (Eram) (southnorth), from limit of 219 Street to first of Mehrshahr bridge, volume of reported traffic is 1893/06 automobiles.

* Mehrshahr, Imam Khomeini Boulevard (Eram) (southnorth), from first of Azadi Boulevard intersection to Valiasr Boulevard intersection, volume of reported traffic is 2039/43 automobiles. 


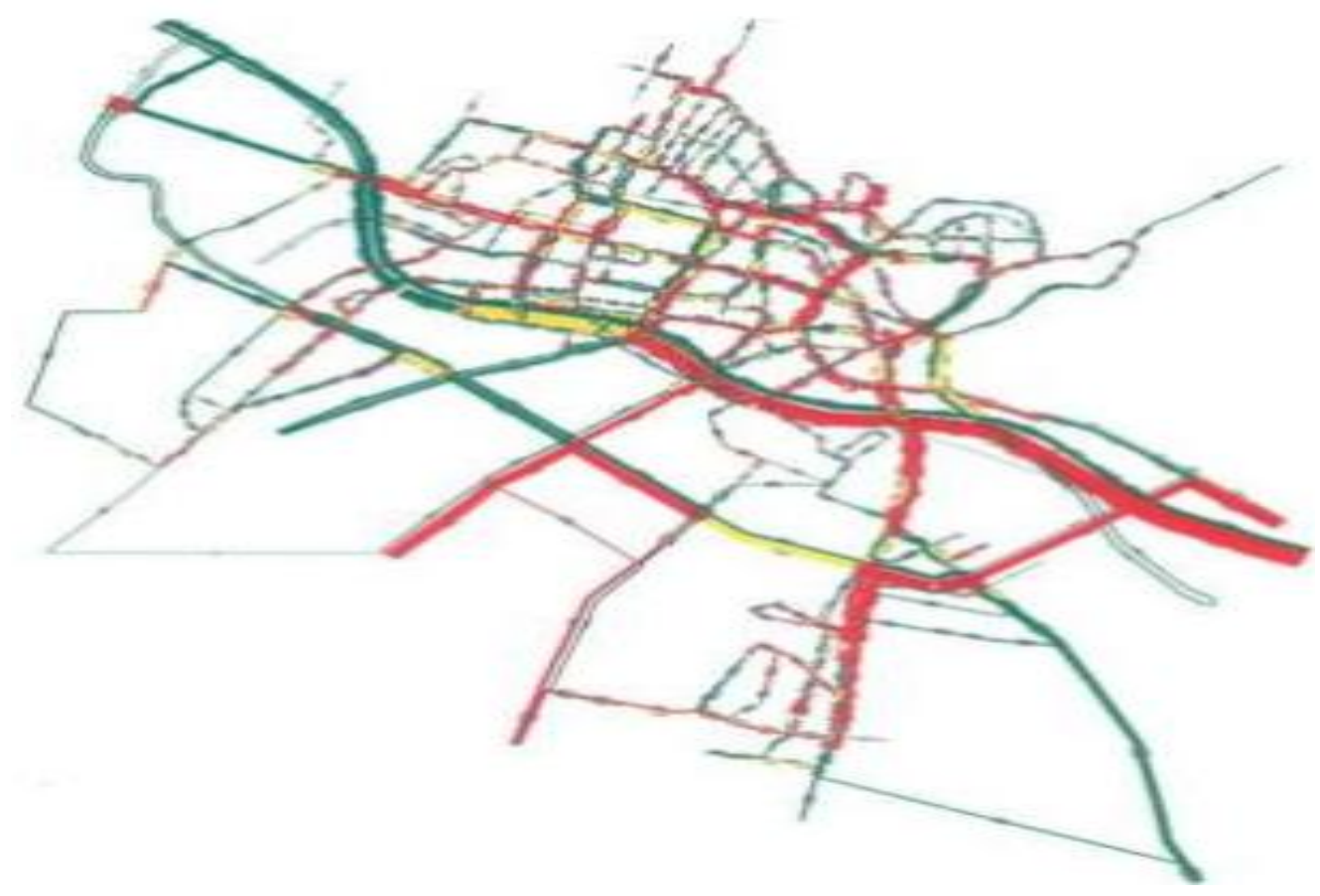

(Volume of travelling vehicles across Karaj roads) Red: Extreme, Yellow: Threshold, Green: Good Map 1: Traffic volume of Karaj

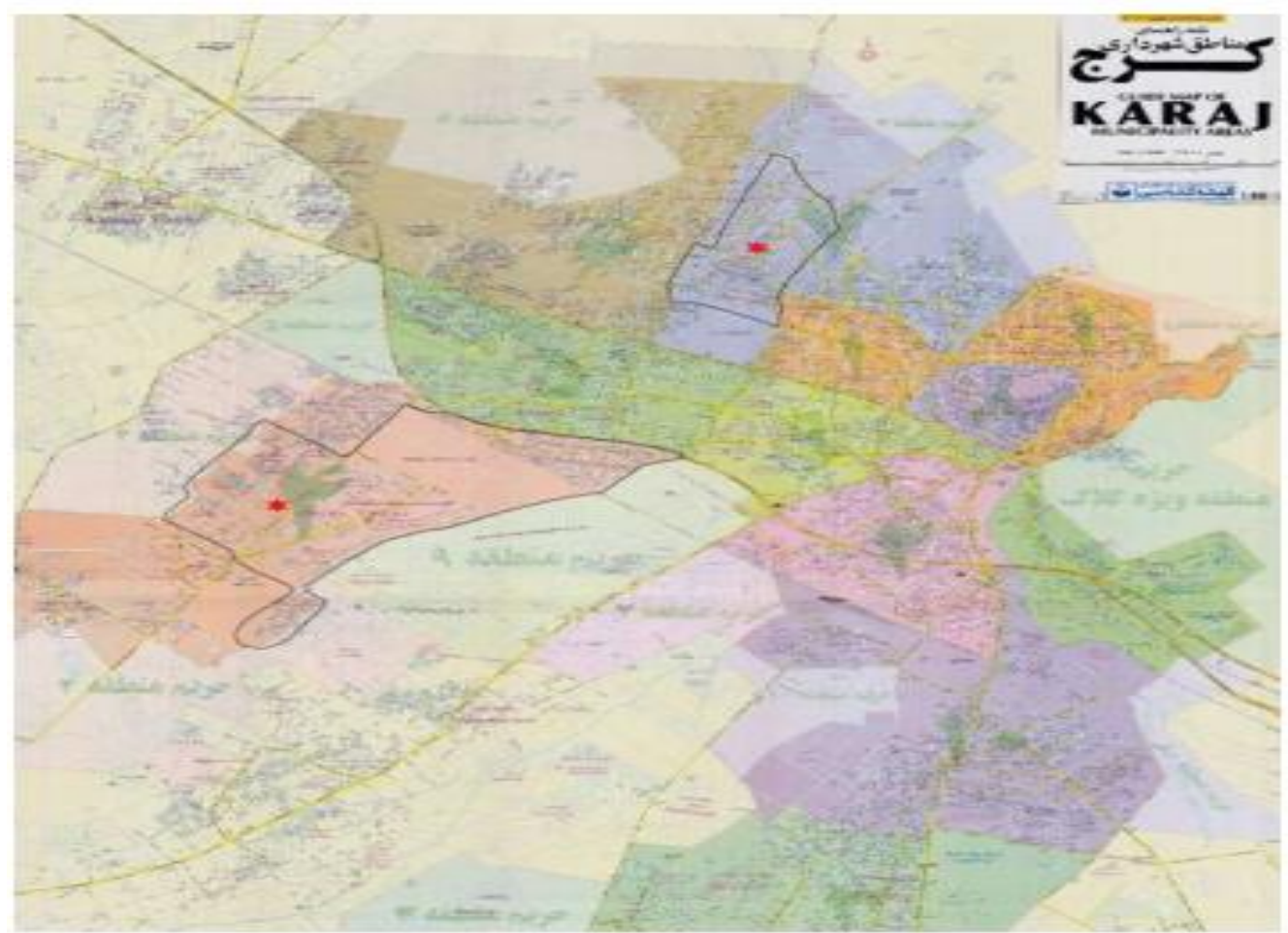

\section{Map 2: Operating limit of Station No.4}

A three layered neural network with back propagation Levenberg/Marquardt training algorithm (BP-LM) will be used for modeling. Fire time and fire load parameters are selected as inputs and losses is selected as target parameter which will be predicted for system. For each parameter, different models with different inputs are developed. Losses neural network model, depicted in Figure 3, indicates predicted values for degree of losses versus the values obtained from results of research. As it is seen, the plots data follow $\mathrm{Y}=\mathrm{X}$ line which indicates that network can predict the losses with high accuracy. According to the plots, correlation coefficient for test data is 0.9977 and for validation data is equal to 0.9999 which represents that the phenomenon is not happened in the developed model. 

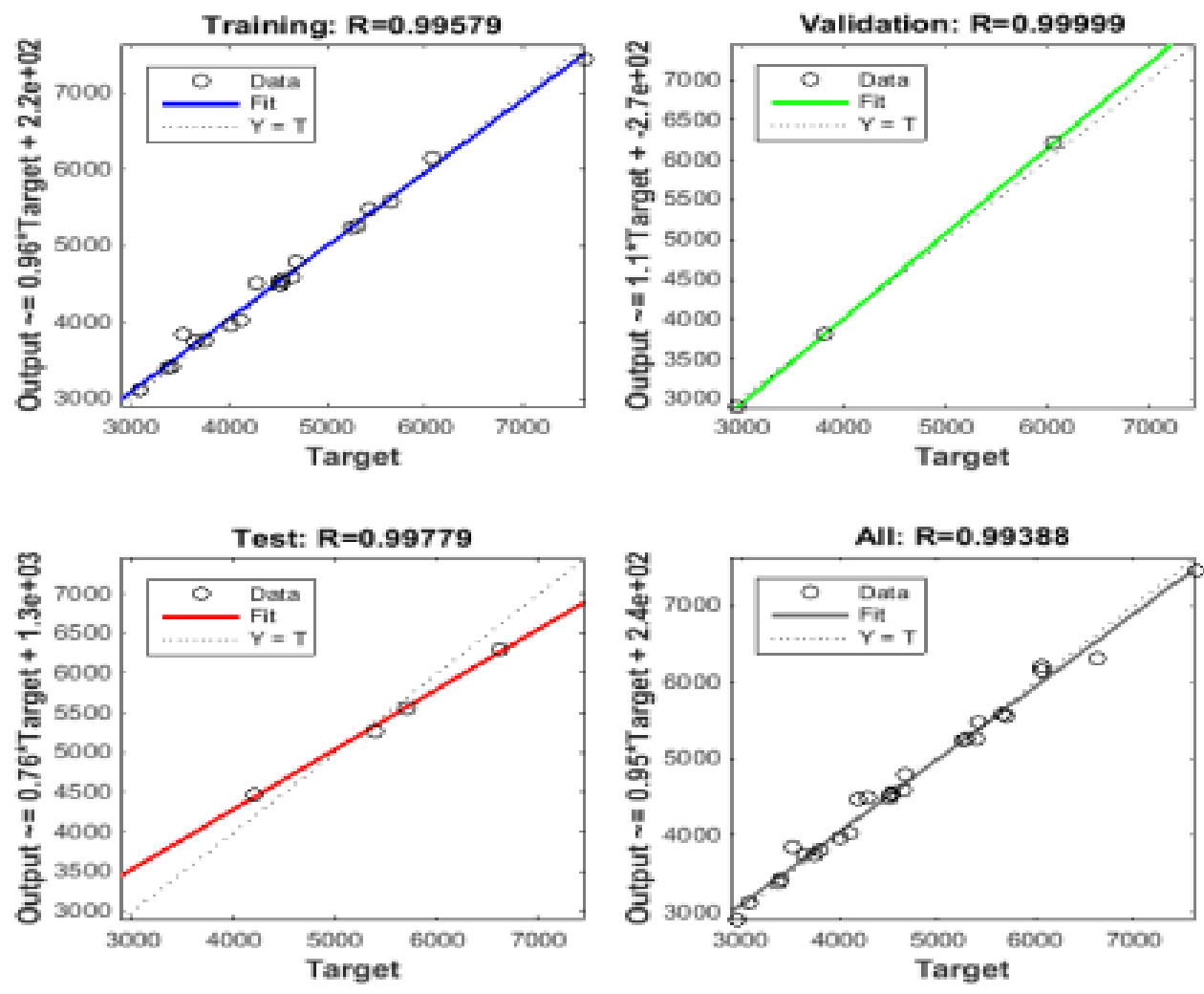

Figure 3: Results of neural network model for losses prediction

\section{CONCLUSION}

After superimposition of traffic volume map (Map 1) and Karaj map (Map 2), the peak traffic points in operational limit of firefighting Station No.4 in Karaj were obtained and as result, the peak traffic points within operational limit were determined. Therefore, given the total number of 11185 fire incidents and rescue missions during 2017 reported to 33 firefighting stations in Karaj $($ Fire $=5398$, Rescue $=5787)$, 405 fire incidents were reported to Station No.4 which was the maximum report comprising the 7.553 percent of all fire missions of Karaj.

Neural network model was used to predict the losses. The results suggest that this network is able to predict the subject with accuracy of 0.9938 percent.

\section{REFERENCES}

[1] AlirezaSarvariSayyed, MajidMazinani, A new tunnel fire detection and suppression system based on camera image processing and water mist jet fans, heliyon , Volume 5, Issue 6, June 2019, e01879.

[2] ChangLiu, MaohuaZhong, XiangliangTian , PeihongZhang, ShuwenLi, Study on emergency ventilation for train fire environment in metro interchange tunnel, Building and Environment, Volume 147, January 2019, Pages 267-283.

[3] MinjiChoi, SeokhoChi , ShuwenLi, Simulation Modelling Practice and Theory Optimal route selection model for fire evacuations based on hazard prediction data, Elsevier Simulation Modelling Practice and Theory , Volume 94, July 2019, Pages 321-333.
[4] JunliLuoa, ZhishengXub , FulinLib, JiamingZhaob, Effect of vehicular blocking scene on smoke spread in the longitudinal ventilated tunnel fire Case Studies in Thermal Engineering, Elsevier, Volume 14, September 2019, 100495.

[5] ZhiguoYan, YuxinZhang, QingchaoGuo , HehuaZhu, YiShen, QinghuaGuo, Numerical study on the smoke control using point extraction strategy in a large crosssection tunnel in fire, Tunnelling and Underground Space Technology, Volume 82, December 2018, Pages 455-467.

[6] NobuoMishimab, TakayukiFuchikamic , A Simulation Study on Fire Evacuation Routes in Primary Stage for a Historic Canal Residential Area, Elsevier Procedia Social and Behavioral Sciences, Volume 216, 6 January 2016, Pages 492-502.

[7] QiZhangab, Scene Design and Simulation Analysis of Fire Accident in Underwater Tunnel, Elsevier Procedia Engineering, Volume 166, 2016, Pages 337-346.

[8] J.PesicaDarko, N.ZigaraIonAnghelbSrdjan , M.Glisovica , Large Eddy Simulation of wind flow impact on fireinduced indoor and outdoor air pollution in an idealized street canyon, Elsevier Journal of Wind Engineering and Industrial Aerodynamics, Volume 155, August 2016, Pages 89-99.

[9] ZhengWei, Fire Safety Design of Indoor Pedestrian Streets of Large Commercial Building, Elsevier Procedia Engineering, Volume 52, 2013, Pages 656-652. 